\title{
E-Tutorial: Pemodelan Dan Simulasi Respon Transien Arus Dan Tegangan Pada Rangkaian RLC Menggunakan ATPDraw
}

\author{
Iswadi HR ${ }^{1,2}$ dan Suwitno ${ }^{1}$ \\ 1. Jurusan Teknik Elektro, Fakultas Teknik, Universitas Riau, Indonesia, 28293 \\ 2. Laboratorium Mesin Mesin Listrik, Fakultas Teknik, Universitas Riau, Indonesia, 28293 \\ E-mail : iswadihr@unri.ac.id atau iswadihr@gmail.com
}

\begin{abstract}
Abstrak
Artikel ini bertujuan untuk membuat alat bantu ajar yang diharapkan dapat mempermudah tenaga pengajar dan mahasiswa dalam memahami mata kuliah Rangkaian Listrik. Contoh kasus yang diambil adalah analisa transien arus dan tegangan pada rangkaian $R L C$ seri yang terdiri dari rangkaian $R L, R C$ dan $R L C$ seri. Alat bantu yang digunakan adalah ATPDraw yang merupakan salah satu perangkat lunak simulasi yang penggunaannya sangat mudah dan bersifat interaktif. Dengan adanya perangkat lunak simulasi ini didapatkan bentuk respon transien arus dan tegangan pada rangkaian $R L C$ seri secara mudah dan cepat jika dibandingkan dengan tanpa alat bantu simulasi. Produk akhir dari alat bantu ini kemudian dikemas dalam format viode untuk menghasilkan sebuah video tutorial. Dengan adanya viodeo tutorial tersebut, maka mahasiswa bisa mempelajari ulang materi tersebut secara mandiri saat di luar jadwal perkuliahan. Pada akhirnya diharapkan pemahaman mahasiswa lebih baik lagi jika dibandingkan dengan tanpa menggunakan viodeo tutorial. Hasil simulasi untuk seluruh contoh kasus sudah divalidasi dengan menggunakan perhitungan manual dan alat bantu lainnya (mathcad). Dari grafik respon transien arus dan tegangan yang dihasilkan dari simulasi ATPDraw didapatkan hasil yang sesuai dengan grafik simulasi menggunakan mathcad.
\end{abstract}

Kata Kunci : E:Tutorial, Respon Transien, Rangkaian RLC, ATPDraw, Mathcad

\begin{abstract}
The aim of this paper is to depelove teaching aid for Electrical Circuit subject. Voltage and current transient analysis in RLC series circuit had been coohsen as examples. It used ATPDraw for analyzing and modeling the circuits. It is hoped that by using this teaching aid and simulation, the result of voltage and current transient in an electrical circuit will be obtained easly and fastly than hand calucated method. The final product of this teaching aid will be converted to a video tutorial. Using this video tutorial, the students can review the subject by themselve. Finally, it is hoped that using this video tutorial, the student's understanding in electrical circuit subject will increase. All of simulation results in these cases study had been compared to hand calculated method and other software (mathcad). From the graphs results, ATPDraw has the same result with mathcad simulation.
\end{abstract}

Key words: E: Tutorial, Transient Responses RLC Circuit, ATPDraw, Mathcad

\section{Pendahuluan}

Mata kuliah Rangkaian Listrik adalah salah satu mata kuliah dasar dan juga termasuk sebagai mata kuliah wajib di jurusan Teknik Elektro Fakultas Teknik Universitas Riau. Untuk program studi Teknik Elektro D3, mata kuliah ini diberikan pada semester I dan semester II dengan nama mata kuliah adalah Rangkaian Listrik I dan Rangkaian Listrik II dan masing masing bobot 2 SKS. Sedangkan untuk program studi Teknik Elektro S1, mata kuliah ini diberikan pada semester II dan semester III dengan nama mata kuliah Rangkaian Listrik I dan Rangkaian Listrik II dengan masing masing bobot sebesar 3 SKS (Suwitno, 2008).

Walaupun mata kuliah ini adalah mata kuliah dasar, namun untuk mengikuti mata kuliah ini peserta kuliah diharapkan memiliki kemampuan prasyarat Matematika yang cukup baik. Materi utama mata kuliah ini adalah analisa rangkaian, yaitu suatu cara untuk 
menghitung besarnya arus maupun tegangan dalam suatu rangkaian listrik dengan berbagai teknik analisa. Analisa rangkaian listrik dapat dibedakan menjadi dua macam, yaitu:1) analisa rangkaian dalam kondisi steady state (mantap) dan 2) analisa rangkaian dalam kondisi transient (peralihan/transien).

Analisa rangkaian dalam kondisi mantap cukup mudah dipahami karena nilai arus dan tegangan dapat dihitung dan digambar secara konvensional dalam waktu yang relatif cepat. Pada dasarnya analisa rangkaian dalam konidisi transien juga dapat dilakukan secara konvensional namun apabila dilakukan secara konvensional akan memerlukan waktu yang cukup lama terutama untuk menggambar grafik respon transien suatu rangkaian.

Seiring dengan perkembangan teknologi informasi, maka perangkat hitung (seperti: komputer) bisa dimanfaatkan untuk mempermudah analisa rangkaian dalam kondisi transien tersebut. Dengan menggunakan komputer dan perangkat lunak pemodelan yang sudah banyak tersedia diharapkan analisa rangkaian transien dapat dilakukan secara cepat. Salah satu perangkat lunak yang banyak digunakan untuk analisa rangkaian listrik dalam kondisi transien adalah ATPDraw (Iswadi-HR et al., 2009) (Danyek, 2005).

Tujuan utama dari artikel ini secara garis besar adalah memperkenalkan dan menggunakan alat bantu ajar berbasiskan pemodelan menggunakan perangkat lunak ATPDraw. Produk akhir alat bantu ajar ini nantinya juga akan dikemas dalam bentuk etutorial, yaitu suatu modul tutorial elektronik dalam format video sehingga dengan adanya e-tutorial tersebut mahasiswa bisa mengulang materi perkulihan saat waktu senggang di luar jadwal perkuliahan dengan demikian pemahaman mahasiswa terhadap materi ajar dapat ditingkatkan secara mandiri.

\section{Respon Transien Rangkaian Seri RC}

Gambar 1. menunjukan sebuah rangkaian seri RC dengan tegangan masukan yang memiliki magnitud sebesar $\mathrm{V}$ seperti ditunjukan pada gambar 2.

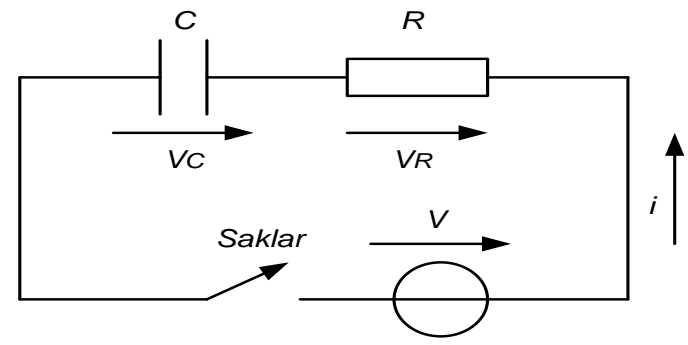

Gambar 1. Rangkaian RC Seri

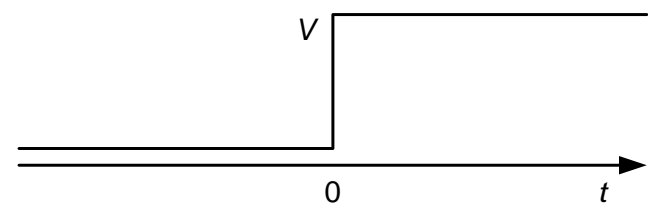

Gambar 2. Tegangan Masukan Step sebesar V

Dari rangkaian pada gambar 1 tersebut dapat diturunkan persamaan tegangan pada kapasitor v $_{\mathrm{C}}$, persamaan tegangan pada resistor $\mathrm{v}_{\mathrm{R}}$ dan persamaan arus i yang mengalir pada rangkaian tersebut seperti dituliskan pada persamaan (1), persamaan (2) dan persamaan (3) (Bird.2003).

$$
\begin{aligned}
v_{C} & =V\left(1-e^{-t / C R}\right) & & \text { Persamaan (1) } \\
v_{R} & =V e^{-t / C R} & & \text { Persamaan (2) } \\
i & =\frac{V}{R} e^{-t / C R} & & \text { Persamaan (3) }
\end{aligned}
$$




\section{Respon Transien Rangkaian Seri RL Terhadap Masukan Step}

Gambar 3. menunjukan sebuah rangkaian seri $R L$ dengan tegangan masukan yang memiliki magnitud sebesar $\mathrm{V}$.

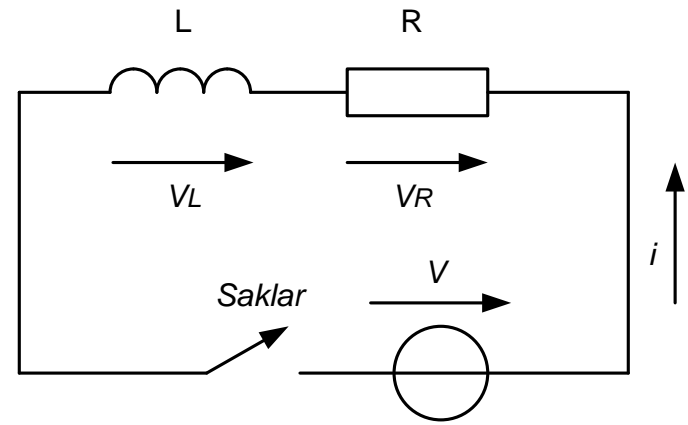

Gambar 3. Rangkaian RL Seri

Dari rangkaian pada gambar 3 tersebut dapat diturunkan persamaan tegangan pada induktor $\mathrm{V}$, persamaan tegangan pada resistor $\mathrm{V}_{\mathrm{R}}$ serta persamaan arus $\mathrm{i}$ yang mengalir pada rangkaian seperti dituliskan pada persamaan (4), persamaan (5) dan persamaan (6) (Bird, 2003).

$$
\begin{aligned}
v_{L} & =V e^{-R t / L} & & \text { Persamaan (4) } \\
v_{R} & =V\left(1-e^{-\frac{R t}{L}}\right) & & \text { Persamaan (5) } \\
i & =\frac{V}{R}\left(1-e^{-\frac{R t}{L}}\right) & & \text { Persamaan (6) }
\end{aligned}
$$

\section{Respon Transien Rangkaian Seri RLC}

Gambar 4. menunjukan sebuah rangkaian seri RLC dengan tegangan masukan yang memiliki magnitud sebesar V.

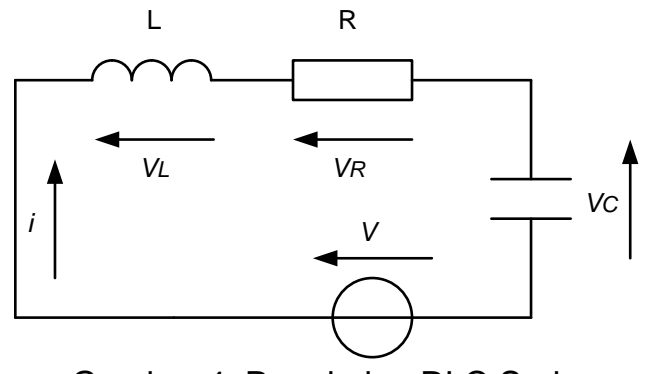

Gambar 4. Rangkaian RLC Seri

Dari rangkaian pada gambar 4. tersebut dapat diturunkan hukum tegangan kirchoff sebagai berikut (Bird, 2003) :

dimana:

$$
V=v_{L}+v_{R}+v_{C} \quad \text { Persamaan (7) }
$$

$$
\begin{aligned}
& v_{L}=L \frac{d i}{d t} \\
& i=C \frac{d v_{c}}{d t}
\end{aligned}
$$

Maka $\mathrm{V}_{\mathrm{L}}$ dapat ditulis sebagai berikut:

$$
\begin{aligned}
& v_{L}=L \frac{d}{d t}\left(C \frac{d v_{c}}{d t}\right)=L C \frac{d^{2} v_{C}}{d t^{t}} \\
& v_{R}=i R=\left(C \frac{d v_{c}}{d t}\right) R=R C \frac{d v_{c}}{d t}
\end{aligned}
$$

Sehingga persamaan (7) dapat ditulis sebagai berikut: 


$$
V=L C \frac{d^{2} v_{C}}{d t^{t}}+R C \frac{d v_{C}}{d t^{t}}+v_{C} \quad \text { Persamaan (8) }
$$

Persamaan (8) adalah persamaan differensial orde 2 yang memiliki 3 kemungkinan penyelesaian (Bird. 2003):

1. Apabila persamaan differensial orde 2 memeliki akar-kar real dan berbeda, maka penyelesaian umunya dapat ditulis sebagai: $v_{C}=A e^{\propto t}+B e^{\beta t}$

Dimana :

$$
\begin{aligned}
& \propto=-\frac{R}{2 L}+\sqrt{\left[\left(\frac{R}{2 L}\right)^{2}-\frac{1}{L C}\right]} \\
& \beta=-\frac{R}{2 L}-\sqrt{\left[\left(\frac{R}{2 L}\right)^{2}-\frac{1}{L C}\right]}
\end{aligned}
$$

2. Apabila persamaan differensial orde 2 memiliki akar tungal, maka penyelesaian umumya dapat ditulis sebagai: $v_{C}=(A+\beta) e^{\propto t}$

Dimana :

$\propto=-\frac{R}{2 L}$

3. Apabila persamaan differensial orde 2 memeliki akar complex, maka penyelesaian umunya dapat ditulis sebagai :

$v_{C}=e^{\alpha t}\{A \cos \beta t+B \sin \beta t)$

Dimana :

$$
\begin{aligned}
& \propto=-\frac{R}{2 L} \\
& \beta=\sqrt{\left[\frac{1}{L C}-\left(\frac{R}{2 L}\right)^{2}\right]}
\end{aligned}
$$

\section{Bahan dan Metode}

Studi kasus yang yang dibahas pada artikel ini adalah analisa transien arus dan tegangan untuk rangkaian RLC seri. Rangkaian ini terdiri dari sebuah sumber DC yang dibebani dengan komponen, RL, RC dan RLC yang disusun secara seri. Adapun metode yang telah dilaksanakan meliputi beberapa tahapan berikut: 1 . Pembuatan model rangkaian seri RLC menggunakan ATPDraw 2. Melihat hasil respon transien tegangan dan arus untuk masing rangkaian seri RLC yang telah dimodelkan tersebut. 3. Memvalidasi model yang telah dibuat menggunakan ATPDraw tersebut dengan mathcad. 4. Pembuatan materi ajar etutorial, yaitu sebuah produk tutorial dalam format video menggunakan Camtasia Studio 5.

3. Hasil dan Pembahasan

\section{Respon Transien Arus dan Tegangan Pada Rangkaian Seri RC Menggunakan}

\section{ATPDraw}

Gambar 4. adalah grafik respon transien arus dan tegangan pada rangkaian $\mathrm{RC}$ seri menggunakan ATPDraw yang dirangkai berdasarkan rangkaian pada gambar 1 dimana $\mathrm{V}=$ 50 volt, $R=50$ ohm dan $C=0,5 \mu \mathrm{F}$.

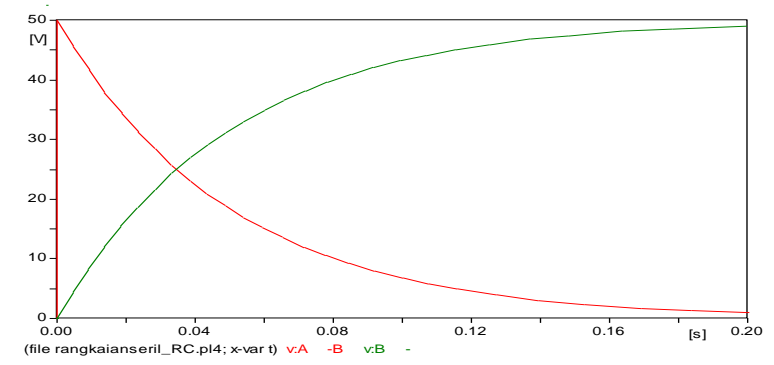

Gambar 4. Tegangan pada Resistor dan Kapasitor pada Rangkaian RC Menggunakan ATPDraw 
Sedangkan gambar 5 . adalah bentuk respon transien arus yang terjadi pada rangkaian seri $\mathrm{RL}$. Masing masing grafik respon transien arus dan tegangan pada gambar 4 dan gambar 5. tersebut kemudian dibandingkan dengan grafik respon transien menggunakan mathcad. Gambar 6. dan 7. menunjukan grafik respon arus dan tegangan pada rangkaian RC menggunakan Mathcad. Dari gambar 4-6 terlihat bahwa grafike transien arus dan tegangan pada rangkaia $R L$ seri menggunakan ATPDraw sama dengan grafik yang dihasilkan oleh Mathcad

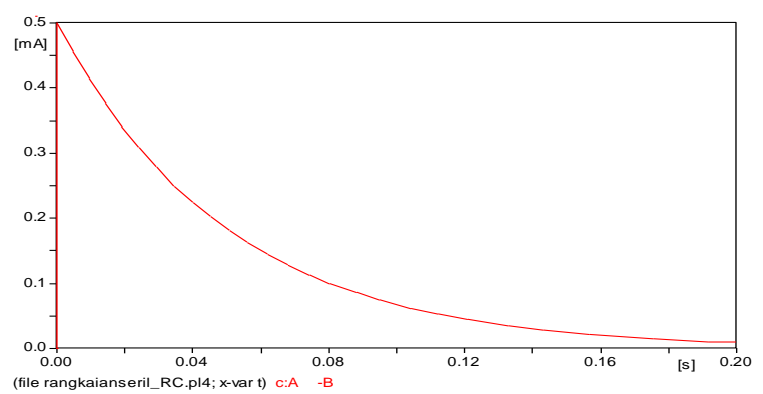

Gambar 5. Arus pada Rangkaian RC Menggunakan ATPDraw

Masing masing grafik respon transien arus dan tegangan pada gambar 4.1. sampai dengan gambar 4.3. tersebut kemudian dibandingkan dengan grafik respon transien menggunakan mathcad. Gambar 4.4. sampai dengan gambar 4.6. berikut menunjukan grafik respon arus dan tegangan pada rangkaian $\mathrm{RC}$ menggunakan Mathcad.

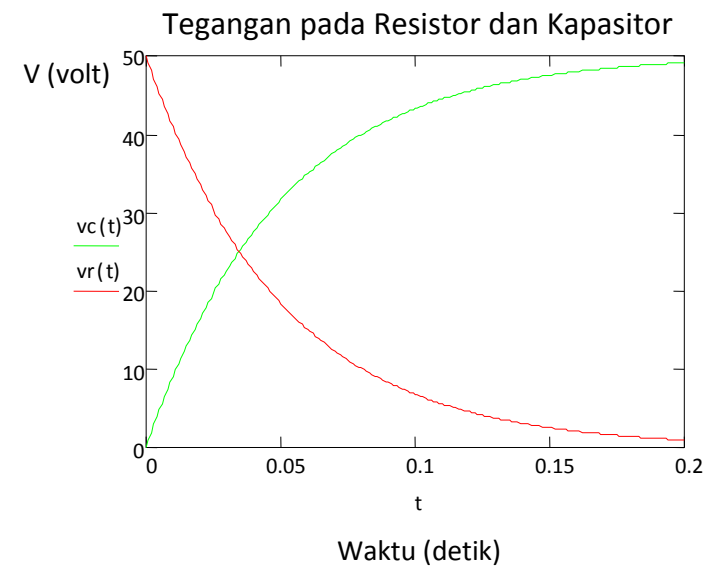

Gambar 6. Tegangan Resitor dan Kapasitor pada Rangkaian RC Menggunakan Mathcad

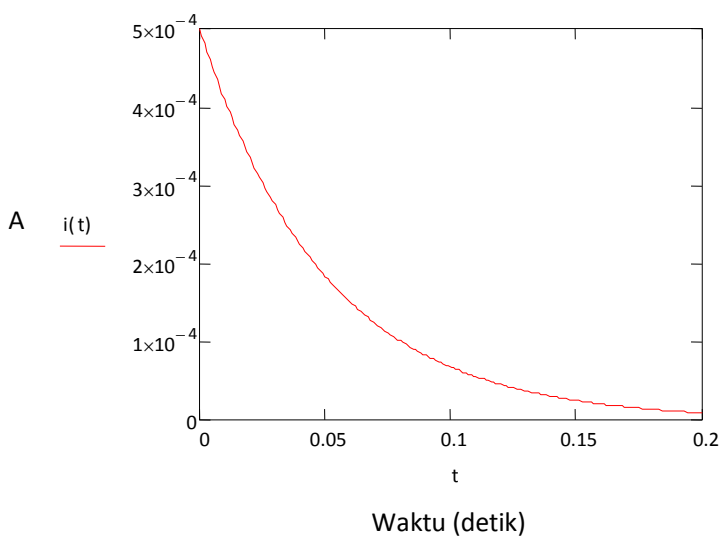

Gambar 7. Arus pada Rangkaian RC Menggunakan Mathcad 
Dari gambar 4. sampai dengan gambar 7 tersebut terlihat bahwa grafik transien arus dan tegangan pada rangkaian RC yang dihasilkan dari pemodelan ATPDraw sudah sama dengan grafik yang dihasilkan oleh mathcad.

Respon Transien Arus dan Tegangan Pada Rangkaian Seri RL Menggunakan

\section{ATPDraw}

Rangkaian seri RL pada gambar 2. kemudian dirangkai menggunakan ATPDraw dengan paramater $v=50$ volt, $R=50 \Omega$ dan $\mathrm{L}=50 \mathrm{mF}$. Rangkaian lalu disimulasikan untuk medapatkan respon transien arus dan tegangan pada masing masing komponen. Gambar 8. dan gambar 9. menunjukan grafik respon transien arus dan tegangan pada rangkaian $\mathrm{RL}$ seri.

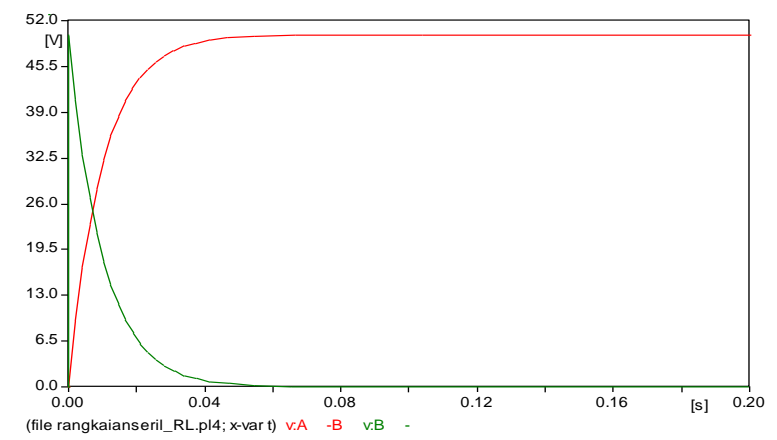

Gambar 8. Tegangan Resistor dan Induktor Rangkaian RL Menggunakan ATPDraw

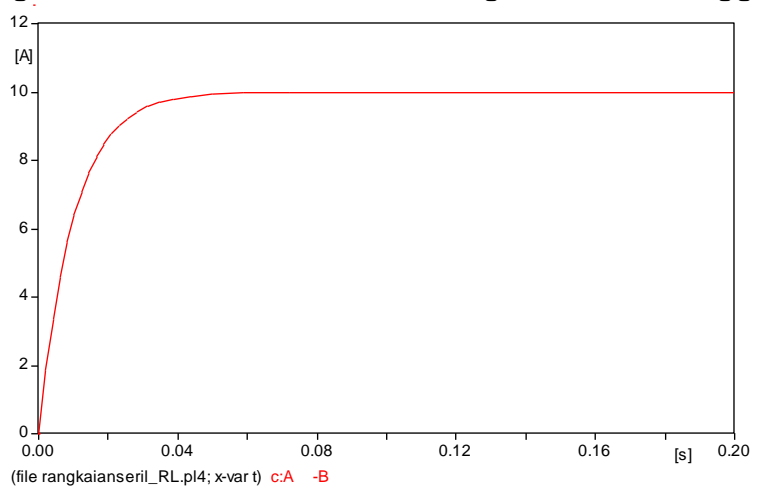

Gambar 9. Arus pada Rangkaian pada Rangkaian RL Menggunakan ATPDraw Masing masing grafik respon transien arus dan tegangan pada gambar 8 dan gambar 9 . tersebut kemudian dibandingkan dengan grafik respon transien menggunakan mathcad. Gambar 10. dan gambar 11. menunjukan grafik respon arus dan tegangan pada rangkaian RC menggunakan Mathcad.

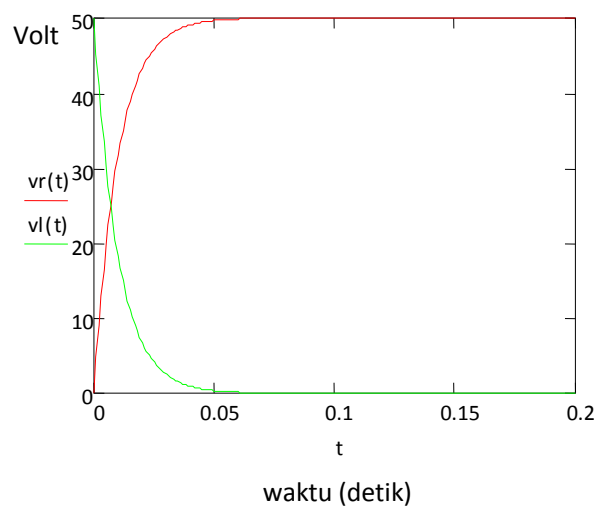

Gambar 9. Tegangan pada Resistor dan Induktor pada Rangkaian RL Menggunakan Mathcad 


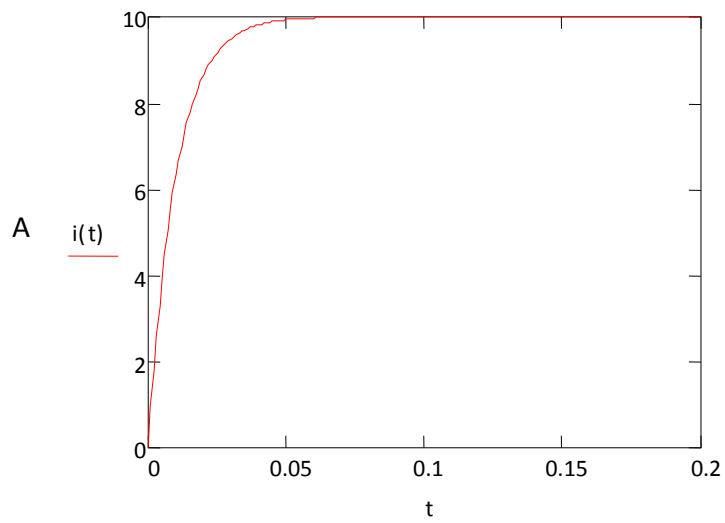

Waktu (detik)

Gambar 11. Arus pada Rangkaian RL Menggunakan Mathcad

Dari gambar 9. sampai dengan gambar 11. Tersebut terlihat bahwa grafik transien arus dan tegangan pada rangkaian $\mathrm{RL}$ yang dihasilkan dari pemodelan ATPDraw sudah sama dengan grafik yang dihasilkan oleh mathcad.

\section{Respon Transien Arus dan Tegangan Pada Rangkaian Seri RLC Menggunakan} ATPDraw

Rangkaian seri RLC pada gambar 4 kemudian dirangkai menggunakan ATPDraw dengan parameter $\mathrm{v}=50$ volt, $R=100 \mathrm{k} \Omega, \mathrm{L}=2 \mathrm{mH}$ dan $\mathrm{C}=5 \mu \mathrm{F}$. Rangkaian tersebut kemudian disimulasikan untuk medapatkan respon transien arus dan tegangan pada masing masing komponen. Gambar 12. dan gambar 13. Menunjukan grafik respon transien arus dan tegangan pada rangkaian $\mathrm{RLC}$ seri.

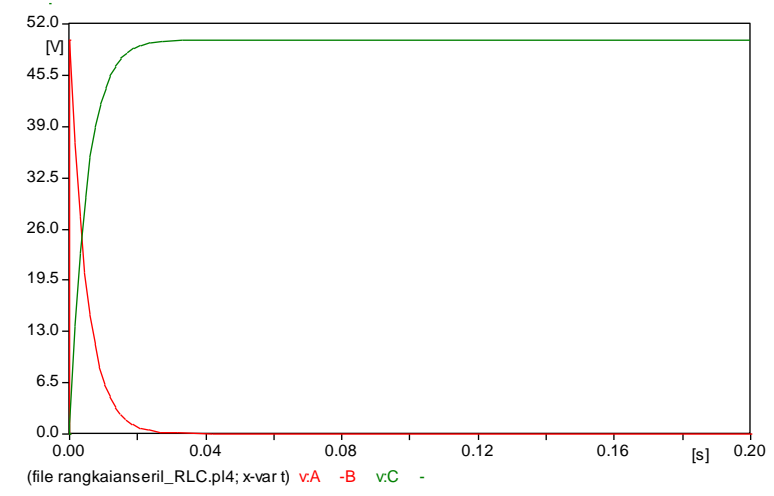

Gambar 12. Tegangan Resistor dan Kapasitor pada Rangkaian RLC Menggunakan ATPDraw

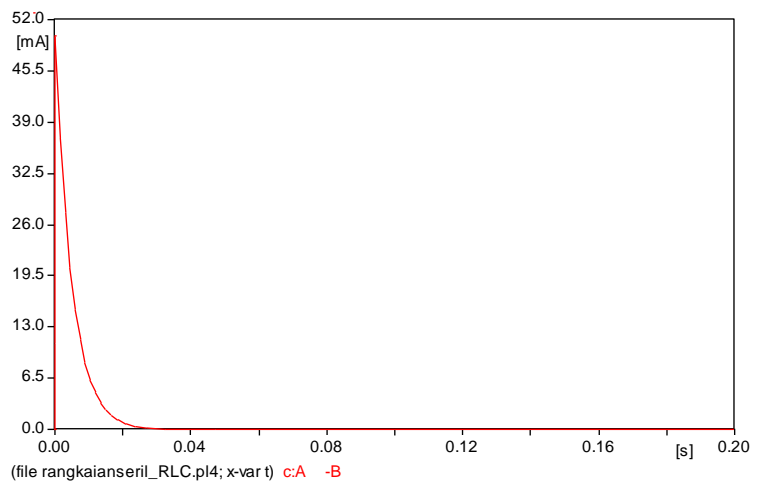

Gambar 13. Arus pada Rangkaian RLC Menggunakan ATPDraw 


\section{Kesimpulan}

Dari analisa yang telah dilakukan dapat disimpulkan sebagai berikut:

1. Pemodelan rangkaian seri RLC menggunakan ATPDraw sangat mudah untuk dilaksanakan sehingga sangat membantu bagi tenaga pengajar dan mahasiswa untuk memahami konsep analisa transien arus dan tegangan pada rangkaian seri RLC.

2. Hasil grafik transien arus dan tegangan pada pemodelan ATPDraw sama dengan pemodelan menggunakan mathcad. Dengan demikian pemodelan yang dilakukan sudah benar.

3. Video tutorial yang dihasilkan dapat digunakan oleh mahasiswa untuk me-review materi perkuliahan tersebut di luar jadwal perkuliahan.

\section{Daftar Pustaka}

[1] Bird, J., 2003. Electrical Circuit Theory and Tachnology. Burlington: Newnes.

[2] Danyek, M., 2005. Comparison of Simulation Tools ATP-EMTP and MATLAB-Simulink for Time Domain Power System Transient Studies. Budapest: Budapest University of Technolgy and Economic.

[3] Degner, T., 2005. Modeling of Distributed Energy Resources with ATP-EMTP. In European ATP-EMTP Users Group Meeting and Conference. Poland, 2005.

[4] Iswadi-HR, Hamzah, A. \& Anhar, 2009. Alat Bantu Ajar Proteksi Sistem Tenaga Listrik Menggunakan ATPDraw dan MATLAB. Laporan Penelitian. Pekanbaru: Universitas Riau.

[5] Priker, L. \& Hoidalen, H.K., 2005. ATPDraw Version 3.5 for Windows 9x/NT/2000/XP User's Manual.

[6] Suwitno, 2008. Usulan Peningkatan Porgram Studi Menjadi Jurusan Teknik Elektro. Dokumen Jurusan Teknik Elektro. Pekanbaru: Universitas Riau. 